\title{
CORRELAÇÃO ENTRE VOLUMETRIA DE FLORESTAS DE EUCALIPTO E PRODUTIVIDADE E CUSTOS DE MÁQUINAS DE COLHEITA DE MADEIRA ${ }^{1}$
}

\author{
Stanley Schettino ${ }^{2}$, Luciano José Minette ${ }^{3}$ e Amaury Paulo Souza ${ }^{4}$
}

\begin{abstract}
RESUMO - A mecanização das atividades de colheita florestal tornou-se imperiosa para a sua sustentabilidade, buscando ganhos de produtividade e redução de custos operacionais. Como a produtividade e o custo operacional das máquinas florestais podem ser influenciados pela volumetria das florestas $\left(\mathrm{m}^{3} / \mathrm{ha}\right)$, o conhecimento dessa correlação vem a ser importante ferramenta de trabalho no planejamento da colheita. Este estudo foi desenvolvido em áreas de colheita de eucalipto no Estado de Minas Gerais, e seu principal objetivo foi analisar técnica e economicamente as atividades de colheita florestal mecanizada, bem como sua correlação com a volumetria das florestas. Para isso, foram aplicadas técnicas estatísticas de regressão linear e análise de correlação entre a variável volumetria das florestas e produtividade e custos operacionais das máquinas de colheita. Os resultados indicaram haver forte correlação entre a volumetria das florestas e a produtividade das máquinas, bem assim com os custos operacionais, demonstrando maiores produtividades das máquinas e menores custos de colheita com o incremento da volumetria das florestas. $O$ feller buncher apresentou maior correlação, seguido das máquinas de extração (skidder e clambunck skidder) e da garra traçadora, sendo esta, provavelmente, mais sensível a outros fatores operacionais. A volumetria das florestas deve ser levada em consideração quando da indicação e dimensionamento das máquinas no momento da colheita, bem como no planejamento das atividades, de forma a aumentar a produtividade das atividades e contribuir para a redução dos custos operacionais.
\end{abstract}

Palavras-chave: Produtividade florestal; Custos operacionais; Colheita florestal.

\section{CORRELATION BETWEEN VOLUMETRY OF EUCALYPTUS FORESTS AND PRODUCTIVITY AND COSTS OF WOOD HARVESTING MACHINES}

\begin{abstract}
The mechanization of forest harvesting activities has become imperative to their sustainability, seeking productivity gains and operating costs reduction. As the operating costs and the productivity of forest machines can be influenced by the volumetry of forests $\left(\mathrm{m}^{3} / \mathrm{ha}\right)$, knowledge of this correlation can be an important tool in the harvest planning. This study was conducted in eucalyptus harvest areas in the state of Minas Gerais. The main objective was to technically and economically evaluate the mechanized harvesting activities as well their correlation with volumetry of forests. For this, were applied linear regression statistics techniques and correlation analysis between the volumetry of forests and the productivity and operating costs of harvesting machines. The results showed a strong correlation between the volumetry of forests and productivity of machines as well as operating costs, demonstrating increase of productivity of the machines and reduction of harvesting costs with increasing volumetry of forests. The feller buncher presents higher correlation, followed by the extraction machineries (skidder and clambunck skidder) and grapple saw, this one probably more susceptible to other operational factors. The volumetry of forests should be considered when indicating and sizing of the machines for harvest, as well as in planning activities in order to increase the productivity of activities and contribute to reduction of operating costs.
\end{abstract}

Keywords: Forest productivity; Operating costs; Forest harvesting.

\footnotetext{
${ }^{1}$ Recebido em 07.04.2014 aceito para publicação em 10.06.2015.

${ }^{2}$ Universidade Federal de Viçosa, Programa de Pós-Graduação em Engenharia Florestal, Viçosa, MG - Brasil. E-mail: <stanley.s.schettino@ufv.br>

${ }^{3}$ Universidade Federal de Viçosa, Centro de Ciências Exatas e Tecnológicas, Departamento de Engenharia Elétrica e de Produção, Viçosa, MG - Brasil. E-mail:<minette@ufv.br>.

${ }^{4}$ Universidade Federal de Viçosa, Centro de Ciências Agrárias, Departamento de Engenharia Florestal, Viçosa, MG - Brasil. E-mail:<amaury@ufv.br>.
} 


\section{INTRODUÇÃO}

O setor florestal brasileiro tem como seus principais produtos, entre outros, celulose e papel, painéis de madeira industrializada, carvão vegetal, madeira serrada, lenha, pellets e biomassa para geração de energia. Contando com uma área de 528 milhões de hectares de florestas nativas ricas em biodiversidade e de 6,66 milhões de hectares de reflorestamento, sendo 5,10 milhões com espécies de Eucalyptus spp. e 1,56 milhão com Pinus spp. (ABRAF, 2013), aliados ao clima e solos favoráveis, esse setor vem experimentando constante desenvolvimento, o que demanda cada vez mais produtos de base florestal.

Visando atender a essa crescente demanda, em um cenário onde a de mão de obra é escassa, a competitividade do setor é crescente e as exigências dos mercados consumidores globalizados são cada vez maiores e a mecanização das atividades de produção de madeira tornou-se imperiosa para a sustentabilidade do negócio florestal. Busca-se, com isso, minimizar os custos de produção, diminuir a dependência de mão de obra, aumentar a produtividade, reduzir índices de acidentes e danos ao meio ambiente e garantir um fluxo contínuo de abastecimento de madeira às unidades consumidoras (OLIVEIRA et al., 2006; SANTOS et al., 2013).

O processo de produção de madeira inicia-se com a produção das mudas nos viveiros, passa pelo preparo de solo e plantio, pelos tratos silviculturais e encerra-se com a colheita, que pode ser definida como um conjunto de operações efetuadas no maciço florestal, que visa preparar e levar a madeira até o local de transporte, fazendo uso de técnicas e padrões estabelecidos com a finalidade de transformá-la em produto final (MACHADO et al., 2014). Pode ser realizada em diferentes sistemas, e a escolha do tipo de colheita deve considerar diversas variáveis.

Entre as diversas atividades necessárias à produção de madeira, a colheita é a etapa mais importante economicamente, visto sua grande representatividade na composição do custo final do produto, podendo, juntamente com o transporte, chegar até $50 \%$ dos custos da madeira posta na indústria (MACHADO; LOPES, 2000), além dos riscos de perdas envolvidos na atividade (JACOVINE et al., 2005). A mecanização da colheita florestal no Brasil, na maioria das vezes, utiliza máquinas com elevado custo de aquisição, exigindo o máximo de aproveitamento delas em todas as suas funções (FONTANA; SEIXAS, 2007), com o objetivo de atingir maiores produtividades e reduzir os custos operacionais (BIRRO et al., 2002).

A produtividade das máquinas florestais pode ser influenciada por diversos fatores, como o volume médio individual das árvores (SIMÕES et al., 2014), a distância de extração (SANTOS et al., 2013), o espaçamento de plantio e a declividade do terreno (LEITE et al., 2014), a eficiência operacional das máquinas (ROCHA et al., 2009) e a produtividade das florestas (FERNANDES et al., 2009), entre outros. Malinovski et al. (2006) identificaram 37 principais variáveis de influência na produtividade das máquinas de colheita de eucaliptos, relacionadas ao povoamento, ao terreno e ao planejamento das operações. Conhecer a produtividade das máquinas em diferentes condições de operação é importante ferramenta de trabalho na indicação e direcionamento das máquinas necessárias para as atividades de mecanização.

O objetivo deste trabalho foi analisar técnica e economicamente as atividades de colheita florestal mecanizada no sistema de árvores inteiras, de forma a determinar a correlação entre a volumetria das florestas e a produtividade das máquinas de colheita, individualmente, bem assim com os custos de cada atividade da colheita mecanizada.

\section{MATERIAL E MÉTODOS}

\subsection{Caracterização da área de estudo}

Os dados foram coletados em áreas de uma empresa florestal localizadas nas regiões do Jequitinhonha/Mucuri e do Médio Vale do Rio Doce, Estado de Minas Gerais, situadas entre os meridianos de $42^{\circ} 17^{\prime} 00^{\prime \prime}$ a $43^{\circ} 25^{\prime} 00^{\prime \prime}$ de longitude a Oeste de Greenwich e os paralelos de $17^{\circ} 05^{\prime} 00^{\prime \prime}$ a $18^{\circ} 50^{\prime} 30^{\prime \prime}$ de latitude a Sul da linha do Equador. A altitude varia entre 800 e $1.100 \mathrm{~m}$. Segundo a classificação climática de Köppen, o clima predominante na região é Aw - tropical chuvoso de savana, ou seja, inverno seco e chuvas máximas no verão, e a estação chuvosa ocorre entre os meses de outubro e março (TONELLO et al., 2006; NASCIMENTO et al., 2011).

De acordo com Leite et al. (1997) e Nascimento et al. (2011), a precipitação pluviométrica média anual de região varia entre 800 e $1.300 \mathrm{~mm}$. A vegetação original era formada predominantemente por florestas (estacional semidecidual), que foram substituídas por pastagens. Os principais tipos de solo que ocorrem na região são: 
LatossoloVermelho (LV), Latossolo Vermelho-Amarelo (LVA), Argissolo Vermelho (PV), ArgissoloVermelhoAmarelo (PVA) e Cambissolo Hálico (CX).

$\mathrm{Na}$ área de estudo, as florestas são, em sua totalidade, cultivadas com eucaliptos em povoamentos de clones híbridos de diferentes produtividades (desde 50 até $370 \mathrm{~m}^{3} / \mathrm{ha}$ ), em regime de primeira rotação com 7 anos de idade, espaçamento 3 x 2,5 m e relevo ondulado, sendo as operações de colheita mecanizada limitadas a $27^{\circ}$ de declividade. Esta, por sua vez, é realizada através do sistema de árvores inteiras ("full-tree"), sistema em que, de acordo com Malinovski et al. (2014), a árvore é derrubada e levada para a margem da estrada ou pátio intermediário, onde é processada em forma de pequenas toras, com menos de $6 \mathrm{~m}$ de comprimento.

Nesta análise, foram utilizadas as seguintes máquinas: feller buncher de esteiras marca John Deere, modelo 759J, equipado com cabeçote Waratah, modelo FS20, utilizado para a derrubada das árvores; skidder marca John Deere, modelo $748 \mathrm{H}$, com pinças e clambunck skidder marca John Deere, modelo 1710D, para extração; e garras traçadoras marca Roder modelo GT 800-S, instaladas em máquinas de esteiras marca Caterpillar, modelo 320FM, para processamento.

\subsection{Coleta e análise de dados}

Os dados foram compilados a partir dos relatórios mensais referentes às atividades florestais da empresa, considerando o período de fevereiro de 2012 a janeiro de 2013.

Nesses relatórios, constavam para cada máquina, em nível de talhão, o número de horas programadas para o trabalho; horas efetivas de trabalho (horas em que as máquinas estiveram realmente trabalhando); as horas paradas e os motivos dessa parada (operacionais ou mecânicos); e os custos operacionais das respectivas máquinas nos meses analisados, expressos em reais por hora trabalhada $(\mathrm{R} \$ / \mathrm{h})$.

Visando indexar os valores e eliminar o efeito da inflação para análises futuras, os valores de custos operacionais foram convertidos em dólar pela cotação média do período, expressos em dólares por hora trabalhada (US\$/h), tendo sido considerada a cotação média de cada mês analisado.

A volumetria dos talhões foi obtida a partir dos resultados dos respectivos Inventários Pré-Cortes de cada área colhida, em nível de talhão, sendo os valores expressos em metros cúbicos por hectare $\left(\mathrm{m}^{3} / \mathrm{ha}\right)$ e volume total do talhão em metros cúbicos $\left(\mathrm{m}^{3}\right)$.

A produtividade de cada máquina e em nível de talhão foi estimada em metros cúbicos de madeira cortada, extraída ou processada por hora efetiva de trabalho $\left(\mathrm{m}^{3} / \mathrm{h}\right)$, conforme a equação:

$$
\mathrm{P}=\frac{\mathrm{V}}{\mathrm{h}}
$$

em que:

$\mathrm{P}=$ produtividade da máquina $\left(\mathrm{m}^{3} / \mathrm{h}\right) ;$

$\mathrm{v}=$ volume total do talhão, em metros cúbicos de madeira $\left(\mathrm{m}^{3}\right)$; e

$\mathrm{h}=$ tempo efetivo de trabalho em cada talhão (horas).

O custo de produção foi obtido de cada máquina em nível de talhão, de acordo com a equação:

$$
\mathrm{CP}=\frac{\mathrm{CO}}{\mathrm{P}}
$$

em que:

$\mathrm{CP}=$ custo de produção (US $\left.\$ / \mathrm{m}^{3}\right)$;

$\mathrm{CO}=$ custo operacional (US $\$ / \mathrm{h}) ; \mathrm{e}$

$\mathrm{P}=$ produtividade da máquina $\left(\mathrm{m}^{3} / \mathrm{h}\right)$.

Para analisar as produtividades e custos de cada máquina, foram utilizados dados de talhões que tiveram $100 \%$ da madeira cortada, extraída ou processada no período de um ano, objeto deste estudo.

De posse dos pares de dados de produtividade dos talhões, produtividade das respectivas atividades e custo unitário por atividade, aplicando técnicas de regressão não linear, foi ajustado, para cada atividade, o seguinte modelo (CLUTTER et al., 1983):

$$
\operatorname{Ln}(\mathrm{Y})=\beta_{0}+\frac{\beta_{1}}{\mathrm{X}}+\varepsilon_{\mathrm{i}}
$$

em que:

$\mathrm{Ln}=$ logaritmo neperiano;

$\mathrm{Y}=$ variável dependente;

$\mathrm{X}=$ variável independente;

$\beta_{0}$ e $\beta_{1}=$ parâmetros dos modelos; e

$\varepsilon_{\mathrm{i}}=$ erro aleatório.

Revista Árvore, Viçosa-MG, v.39, n.5, p.935-942, 2015 
As equações ajustadas foram avaliadas através do coeficiente de determinação $\left(\mathrm{R}^{2}\right)$, do coeficiente de variação $(\mathrm{CV} \%)$, pelo coeficiente de correlação entre os valores observados e estimados ao quadrado $\left(\mathrm{Ry} \hat{y}^{2}\right)$ e análise gráfica de dispersão dos valores observados em relação aos estimados pelas equações, conforme metodologia estabelecida por Jayaraman (1999).

Foi avaliado se as produtividades e os custos de produção das máquinas envolvidas no estudo apresentam associação com a volumetria das florestas. Para isso, foi obtido o grau de associação, efetuando-se a análise da matriz de coeficiente da correlação (r) de Pearson, pelo teste t a $5 \%$ e $1 \%$ de probabilidade.

\section{RESULTADOS}

\subsection{Produtividade por máquina}

O modelo escolhido para a estimação das produtividades das máquinas em relação à volumetria das florestas, em geral, ajustou-se bem aos dados, haja vista as estimativas do coeficiente de determinação, do coeficiente de variação e do coeficiente de correlação, além dos gráficos de dispersão (Tabela 1 e Figura 1).

Observando a Tabela 1, pode-se constatar que o sinal positivo do coeficiente de correlação (r) de Pearson, com a variável produtividade das máquinas $(\mathrm{P}<0,01$ para feller buncher e skidder/skidder clambunck e $\mathrm{P}<$ 0,05 para garra traçadora), evidencia o aumento da eficiência das máquinas com o incremento da volumetria das florestas, tendo sido este menor com a garra traçadora.

\subsection{Custo de produção por máquina}

Para a estimação dos custos de produção por máquina em relação à volumetria das florestas, o modelo escolhido, em geral, ajustou-se bem aos dados, haja vista as estimativas do coeficiente de determinação, do coeficiente de variação e do coeficiente de correlação, além dos gráficos de dispersão (Tabela 2 e Figura 2).

Por sua vez, a análise da Tabela 2 permite constatar que o sinal negativo do coeficiente de correlação (r) de Pearson com a variável custo de produção $(\mathrm{P}<0,01$ para feller buncher e skidder/skidder clambunck e não significativo para a garra traçadora) evidencia a diminuição do custo de produção das máquinas com o incremento da volumetria das florestas, tendo sido este não significativo com a garra traçadora. Mesmo assim, a análise da Figura 2 permite afirmar que existe ligeira tendência de redução de custos de produção da garra traçadora com o incremento da volumetria das florestas.

\section{DISCUSSÃO}

\subsection{Estimativa da produtividade das máquinas}

De acordo com a Tabela 1 e a Figura 1, verifica-se que a produtividade das máquinas de colheita mecanizada apresenta, em maior ou menor grau, variação positiva em resposta ao incremento nos índices de volumetria das florestas, sendo a relação diretamente proporcional.

O feller buncher é a máquina que apresenta, positivamente, a maior resposta à volumetria da floresta, e o acréscimo de produtividade desse trator é diretamente proporcional ao incremento na volumetria dos povoamentos, corroborando os resultados encontrados por Fernandes et al. (2009) e Simões et al. (2014). De acordo com Oliveira Junior et al. (2009), isso é verificado devido ao volume médio individual das árvores, que

Tabela 1 - Equações ajustadas de produtividade das máquinas $\left(\mathrm{m}^{3} / \mathrm{h}\right)$ e coeficiente de correlação de Pearson (r), considerando a volumetria das florestas $\left(\mathrm{m}^{3} / \mathrm{ha}\right)$.

Table 1 -Adjusted equations of machine productivity $\left(\mathrm{m}^{3} / \mathrm{h}\right)$ and Pearson's correlation coefficient ( $r$ ) considering the forests volumetry $\left(m^{3} / h a\right)$.

\begin{tabular}{lccccc}
\hline Máquina & Equações & $\mathrm{R}^{2}$ & $\mathrm{CV} \%$ & $\mathrm{R}_{\mathrm{yy}}^{2}$ & $\mathrm{r}$ \\
\hline Feller Buncher & $\operatorname{Ln}\left(m^{3} / h\right)=4,687838-\frac{122,732}{m^{3} / h a}$ & 0,63 & 39,32 & $97,98 \%$ & $0,6345^{*}$ \\
Skidder/Clambunck & $\operatorname{Ln}\left(m^{3} / h\right)=4,245467-\frac{25,8601}{m^{3} / h a}$ & 0,25 & 19,10 & $98,35 \%$ & $0,2714 *$ \\
Garra Traçadora & $\operatorname{Ln}\left(m^{3} / h\right)=3,77793-\frac{6,92162}{m^{3} / h a}$ & 0,11 & 12,52 & $99,24 \%$ & $0,2075 * *$ \\
\hline
\end{tabular}

Onde: * significativo a $5 \%$ e $1 \%$ de probabilidade e $* *$ significativo a $5 \%$ de probabilidade, pelo teste t com n-2 graus de liberdade. 

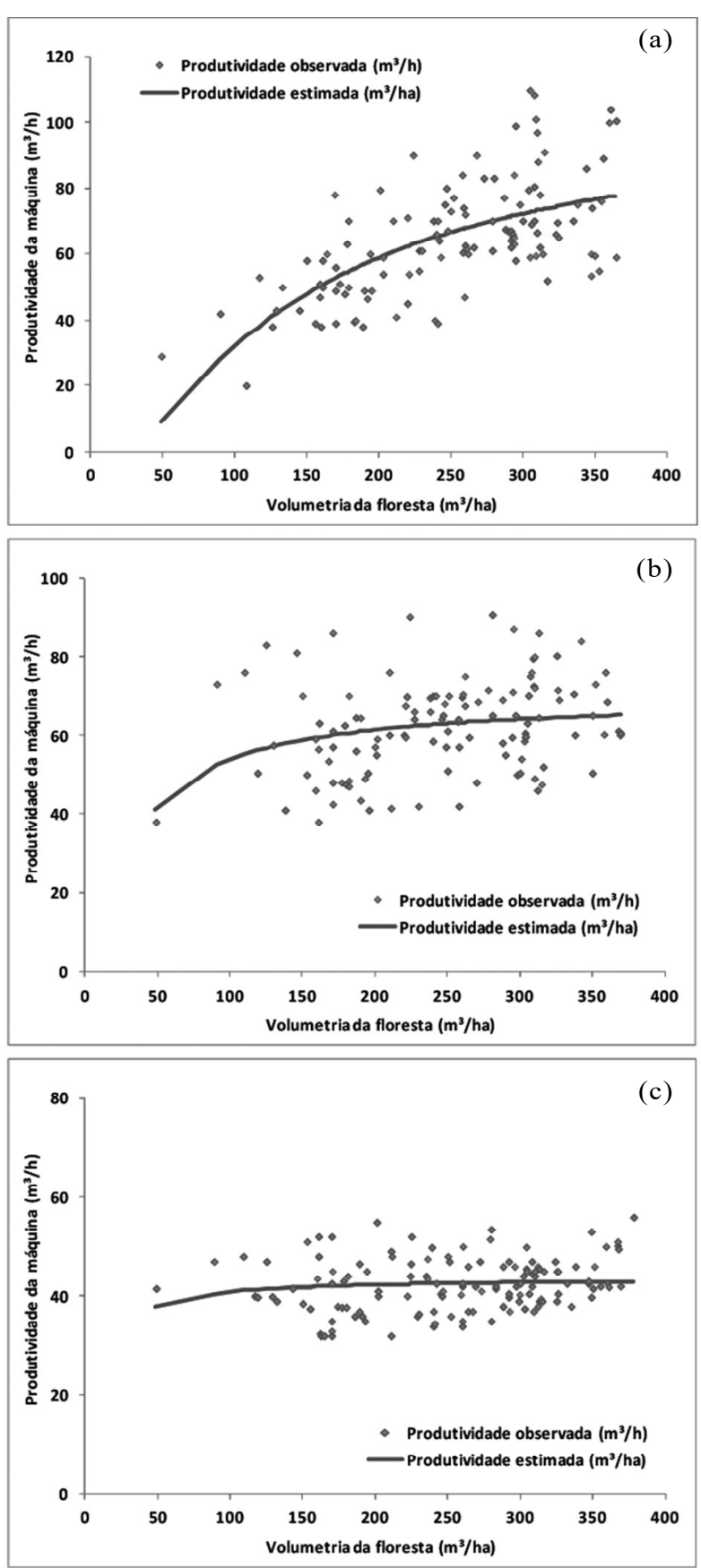

Figura 1 - Relação entre os valores observados e estimados de produtividades das máquinas de colheita feller buncher (a), skidder/clambunck (b) e garra traçadora (c), em função da volumetria da floresta.

Figure 1-Relationship between the observed and estimated values of productivity of harvesting machines feller buncher (a), skidder/clambunck (b) and grapple saw (c), according to forests volumetry. tende a ser maior quanto maior a volumetria das florestas, considerando o mesmo espaçamento e número de árvores por hectare, como é caso deste estudo. Esses autores afirmaram, ainda, ser possível pressupor que o tempo gasto para cortar uma árvore de $0,11 \mathrm{~m}^{3}$ seja igual ao de outra de $0,25 \mathrm{~m}^{3}$. Dessa forma, o rendimento do feller buncher em volume por unidade de tempo cresce à medida que aumenta o volume médio por árvore.

Por sua vez, o sistema de extração mecanizado utilizando skidder e clambunck skidder também sofre influência positiva do acréscimo de volumetria das florestas, embora tal fato não ocorra nas mesmas proporções verificadas para o feller buncher. Pode-se inferir que o acréscimo em produtividade dessas máquinas está relacionado à altura das árvores (comprimento, após derrubadas) que, em povoamentos de maior produtividade, tende a ser maior, pois, fixando-se a área da pinça do skidder e, ou, do clambunck skidder $\left(\mathrm{em} \mathrm{m}^{2}\right)$, tanto maior será o volume arrastado quanto maior for o comprimento das árvores. Embora não tenham sido levadas em consideração neste estudo, a distância de arraste e a declividade do terreno são fatores que influenciam a produtividade do conjunto skidder e clambunck skidder, pois, conforme Oliveira et al. (2006), quanto mais acidentado o relevo e mais distantes os feixes para o arraste, menor a produtividade das máquinas, resultado corroborado por Santos et al. (2013).

Embora as demais máquinas tenham-se mostrado bastante sensíveis ao incremento de volumetria das florestas, a mesma tendência não foi observada para a garra traçadora, tendo sido, neste estudo, evidenciada a baixa sensibilidade dessa máquina à produtividade das florestas, embora essa correlação tenha sido positiva. Fernandes et al. (2009) concluíram que o rendimento da garra traçadora é fortemente afetado pelo volume de madeira e pelo arranjo dos feixes na pilha, em relação diretamente proporcional. Outros autores afirmaram que, entre outros fatores, o volume médio individual das árvores destaca-se como o de maior influência sobre a produtividade da garra traçadora (MALINOVSKI et al., 2006; SIMÕES et al., 2014). A diferença encontrada neste estudo pode ser devida ao comprimento dos toretes, neste caso com $3 \mathrm{~m}$ de comprimento, em que os resultados apresentados por Lopes et al. (2008), Rocha et al. (2009) e Simões et al. (2014) foram baseados em estudos em que a madeira era processada em toretes maiores que 5,70 m de comprimento. Dessa forma, os resultados apresentados neste estudo permitem inferir que, à medida 
Tabela 2 - Equações ajustadas de custo de produção das máquinas (US\$ $/ \mathrm{m}^{3}$ ) e coeficiente de correlação de Pearson (r), considerando a volumetria das florestas $\left(\mathrm{m}^{3} / \mathrm{ha}\right)$.

Table 2 - Adjusted equations for machines production cost $\left(U S \$ / m^{3}\right)$ and Pearson's correlation coefficient ( $\left.r\right)$ considering the forests volumetry $\left(m^{3} / h a\right)$.

\begin{tabular}{lccccc}
\hline Máquina & Equações & $\mathrm{R}^{2}$ & $\mathrm{CV} \%$ & $\mathrm{R}_{y y}^{2}$ & $\mathrm{r}$ \\
\hline Feller Buncher & $\operatorname{Ln}\left(U S \$ / m^{3}\right)=-0,216877+\frac{54,38101}{m^{3} / h a}$ & 0,52 & 30,90 & $96,82 \%$ & $-0,5540^{*}$ \\
Skidder/Clambunck & $\operatorname{Ln}\left(U S \$ / m^{3}\right)=-0,383953+\frac{46,70121}{m^{3} / h a}$ & 0,47 & 27,50 & $97,24 \%$ & $-0,4664 *$ \\
Garra Traçadora & $\operatorname{Ln}\left(U S \$ / m^{3}\right)=-0,010265+\frac{1,998449}{m^{3} / h a}$ & 0,03 & 19,23 & $98,22 \%$ & $-0,1066 \mathrm{~ns}$ \\
\hline
\end{tabular}

Onde: * - significativo a $5 \%$ e $1 \%$ de probabilidade e ns - não significativo, pelo teste t com n-2 graus de liberdade.

que aumenta a volumetria das florestas, aumentam também o volume médio individual e o peso das árvores, o que torna mais difícil o seu manuseio durante a etapa de processamento com a garra traçadora.

\subsection{Estimativa do custo de produção das máquinas}

De acordo com a Tabela 2 e a Figura 2, verifica-se que o custo de produção das máquinas de colheita mecanizada sofre, em maior ou menor grau, variação em resposta ao incremento nos índices de volumetria das florestas, em que essa relação se dá de forma inversamente proporcional. Esse comportamento se deve ao acréscimo de produtividade das máquinas de colheita, à medida que aumenta a volumetria das florestas, pois, dado um mesmo custo horário da máquina, com o acréscimo de sua produtividade, observou-se redução no custo de produção.

Estudos realizados por Moreira et al. (2004) indicaram que, à medida que aumentou a volumetria das florestas, o custo de produção do feller buncher decresceu, corroborando os resultados deste estudo. Também, em seu estudo, Fernandes et al. (2009) concluíram que, à medida que a produtividade da floresta aumentou, a do feller buncher também tendeu a aumentar, e os valores do custo de produção tiveram tendência em diminuir, indicando que a produtividade do talhão influenciou o custo de produção dessa máquina de forma inversamente proporcional. Ainda assim, quando se considera um sistema de colheita em que o feller buncher é apenas um dos componentes desse sistema, a análise do custo do corte isoladamente não pode ser conclusiva, uma vez que as demais máquinas sofrem influência da volumetria da floresta de forma diferenciada, em comparação com o feller buncher. Já para o conjunto skidder e skidder clambunck os resultados confirmaram a expectativa de decréscimo do custo unitário de extração de madeira à medida que aumenta a volumetria das florestas, embora esse decréscimo seja em menor proporção que o verificado com o feller buncher. Essa atividade é bastante sensível a outros fatores operacionais, como o relevo e a distância de arraste (MALINOVSKI et al., 2006; OLIVEIRA et al., 2006). De fato, Santos et al. (2013) verificaram que o custo da atividade chega a variar mais de $140 \%$ para distâncias entre 100 e $360 \mathrm{~m}$.

Por sua vez, a garra traçadora mostrou-se pouco sensível a variações na volumetria das florestas, tendo seu custo de produção apresentado variação média pouco significativa com a variação da volumetria das florestas. Diversos estudos têm apontado que essa máquina vem-se mostrando bastante sensível às condições operacionais locais, como nível de treinamento dos operadores, logística de suprimento de peças e combustíveis, tamanho e distribuição dos pátios de processamento e comprimento dos toretes, entre outros (MALINOVSKI et al., 2006; FIEDLER et al., 2008; LOPES et al., 2008; FERNANDES et al., 2009), as quais, conjunta ou isoladamente, podem vir a neutralizar possíveis reduções de custo de produção decorrentes do incremento na volumetria das florestas.

\section{CONCLUSÕES}

A produtividade das máquinas de colheita de madeira mecanizada apresentou correlação positiva com o incremento na volumetria das florestas, tendo sido esta diretamente proporcional. O custo de produção das máquinas, por sua vez, apresentou correlação negativa, inversamente proporcional, indicando a 

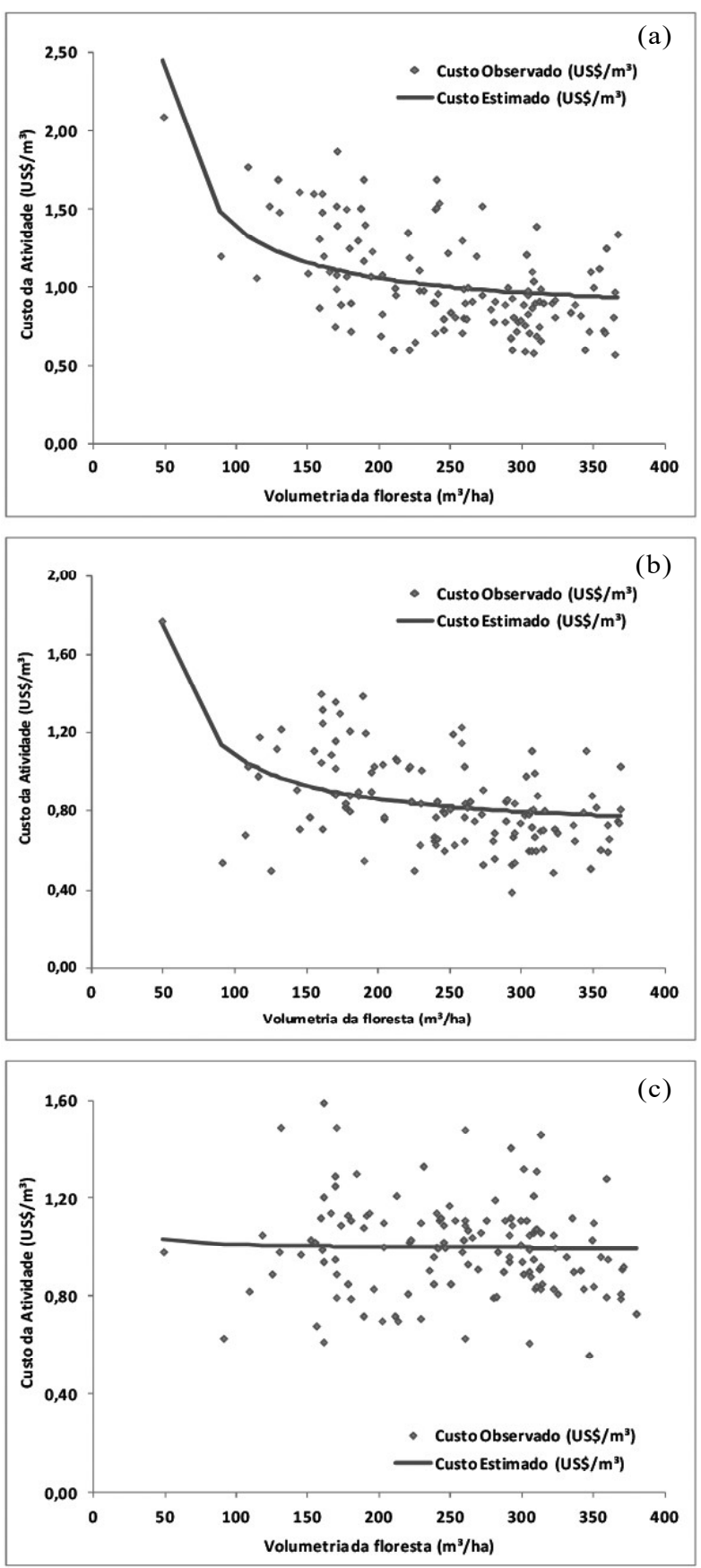

Figura 2 - Relação entre os valores observados e estimados de custos operacionais das máquinas de colheita feller buncher (a), skidder/clambunck (b) e garra traçadora (c), em função da volumetria da floresta.

Figure 2-Relationship between the observed and estimated values of operating costs of harvesting machines feller buncher (a), skidder/clambunck (b) and grapple saw (c), according to forests volumetry. diminuição do custo de produção com o aumento da volumetria das florestas.

O feller buncher foi a máquina que apresentou maior correlação na volumetria das florestas com os índices analisados, seguido pelo conjunto skidder e clambunck skidder e pela garra traçadora, tendo esta apresentado correlação muito baixa.

Nos casos de sistemas de colheita semimecanizados, em florestas de qualquer volumetria, a garra traçadora pode ser opção para o processamento da madeira, independentemente da forma como foi colhida e, ou, extraída, sem prejuízo da produtividade da máquina e do custo operacional da atividade.

\section{REFERÊNCIAS}

ABRAF - Associação Brasileira de Produtores de Florestas Plantadas. Anuário Estatístico ABRAF 2013. Brasília, ABRAF: 2013. 148 p.

BIRRO, M. H. B.; MACHADO, C.C.; SOUZA, A.P.; MINETTI, L.J. Avaliação técnica e econômica da extração de madeira de Eucalipto com "track-skidder" em região montanhosa. Revista Árvore, v. 26, n.5, p. 525-532, 2002.

CLUTTER, J.L.; FORTSON, J.C.; PIENAAR, L.V.; BRISTER, G.H.; BAILLEY, R.L. Timber management: A quantitative approach. Hoboken, NJ, John Wiley \& Sons Inc., 1983. 333 p.

FIEDLER, N.C.; ROCHA, E.B.; LOPES, E.S. Análise da produtividade de um sistema de colheita de árvores inteiras no norte do estado de Goiás. Floresta, v. 38, n. 4, p. 577-586, 2008.

FONTANA, G.; SEIXAS, F. Avaliação ergonômica do posto de trabalho de modelos de "forwarder" e "skidder". Revista Árvore, v. 31, n. 1, p. 71-81, 2007.

FERNANDES, H.C.; LOPES, S.E.; TEIXEIRA, M.M.; MINETTE, L.J.; RINALDI, P.C.N.; BERNARDES, A.M. Avaliação das características técnica e econômica de um sistema de colheita florestal de árvores inteiras. Scientia Forestalis, v. 37, n. 83, p. 225-232, 2009.

JACOVINE, L.A.G., MACHADO, C.C.; SOUZA, A.P.; LEITE, H.G.; MINETTI, L.J. Avaliação da qualidade operacional em cinco subsistemas de 
colheita florestal. Revista Árvore, v. 29, n.3, p. 391-400, 2005.

JAYARAMAN, K. A statistical manual for forestry research. Bangkok: FAO, 1999. 231 p.

LEITE, E.S.; MINETTE, L.J.; FERNANDES, H.C.; SOUZA, A.P.; AMARAL, E.J.; LACERDA, E.G. Desempenho do harvester na colheita de eucalipto em diferentes espaçamentos e declividades. Revista Árvore, v.38, n.1, p. 95-102, 2014

LEITE, F.P.; BARROS, N.F.; SANS, L.M.A.; FABRES, A.S. Regime hídrico do solo sob povoamento de eucalipto, floresta nativa e pastagem, na região de Guanhães-MG. Revista Árvore, v. 21, n.4, p. 455-462, 1997.

LOPES, S.E.; FERNANDES, H.C.; SANTOS, N.T.; RINALDI, P.C.N. Avaliação técnica e econômica de uma garra traçadora operando em diferentes produtividades. Scientia Forestalis, v. 36, n. 79, p. 215-222, 2008.

MACHADO, C.C.; LOPES, E.S. Análise da influência do comprimento de toras de eucalipto na produtividade e custo da colheita e transporte florestal. Cerne, v. 6, n. 2, p. 124-129, 2000.

MACHADO, C.C.; SILVA, E.N.; PEREIRA, R.S.; CASTRO, G.P. O setor florestal brasileiro e a colheita florestal. In: MACHADO, C.C. (Ed.). Colheita Florestal. 3 ed. Viçosa, MG, Ed. UFV, 2014. p. 15-45.

MALINOVSKI, R.A.; MALINOVSKI, R.A.; MALINOVSKI, J.R.; YAMAJI, F.M. Análise das variáveis de influência na produtividade das máquinas de colheita de madeira em função das características físicas do terreno, do povoamento e do planejamento operacional florestal.

Floresta, v. 36, n. 2, p. 169-182, 2006.

MALINOVSKI, J.R.; CAMARGO, C.M.S.; MALINOVSKI, R.A.; MALINOVSKI, R.A.; CASTRO, G.P. Sistemas. In: MACHADO, C.C. (Ed.). Colheita Florestal. 3 ed. Viçosa, MG, Ed. UFV, 2014. p. 178-205.
MOREIRA, F.M.T.; SOUZA, A.P.; MACHADO, C.C.; MINETTI, L.J.; SILVA, K.R. Avaliação operacional e econômica do "Feller-Buncher" em dois subsistemas de colheita de florestas de eucalipto. Revista Árvore, v. 28, n.2, p. 199 205, 2004

NASCIMENTO, A.C.; LEITE, A.M.P.; SOARES, T.S.; FREITAS, L.D. Avaliação técnica e econômica da colheita florestal com fellerbuncher. Cerne, v. 17, n. 1, p. 9-15, 2011.

OLIVEIRA JUNIOR, E.D.; SEIXAS, F. BATISTA, J.L.F. Produtividade de feller-buncher em povoamento de eucalipto em relevo acidentado. Floresta, v. 39, n. 4, p. 905-912, 2009.

OLIVEIRA, R.J.; MACHADO, C.C.; SOUZA, A.P.; LEITE, H.G. Avaliação técnica e econômica da extração de madeira de eucalipto com "clambunck skidder". Revista Árvore, v. 30, n. 2 , p. $267-275,2006$.

ROCHA, E.B.; FIEDLER, N.C.; ALVES, R.T.; LOPES, E.S.; GUIMARÃES, P.P.; PERONI, L. Produtividade e custos de um sistema de colheita de árvores inteiras. Cerne, v. 15, n. 3, p. 372-381, 2009.

SANTOS, P.H.A.; SOUZA, A.P.; MARZANO, F.L.C.; MINETTE, L.J. Produtividade e custos de extração de madeira de eucalipto com clambunck skidder. Revista Árvore, v. 37, n.3, p. 511-518, 2013 .

SIMÕES, D.; FENNER, P.T.; ESPERANDINI, M.S.T. Produtividade e custos do fellerbuncher e processador florestal em povoamento de eucalipto de primeiro corte. Ciência Florestal, v. 24, n. 3, p. 621-630. 2014.

TONELLO, K.C.; DIAS, H.C.T.; SOUZA, A.L.; RIBEIRO, C.A.A.S; LEITE, F.P. Morfometria da bacia hidrográfica da Cachoeira das Pombas, Guanhães - MG. Revista Árvore, v. 30, n.5, p. $849-857,2006$ 